Historic, Archive Document

Do not assume content reflects current scientific knowledge, policies, or practices. 

Forest Service

Technology \& Development

Program

2300-Recreation

June 1995

9523-2840-MTDC

ins

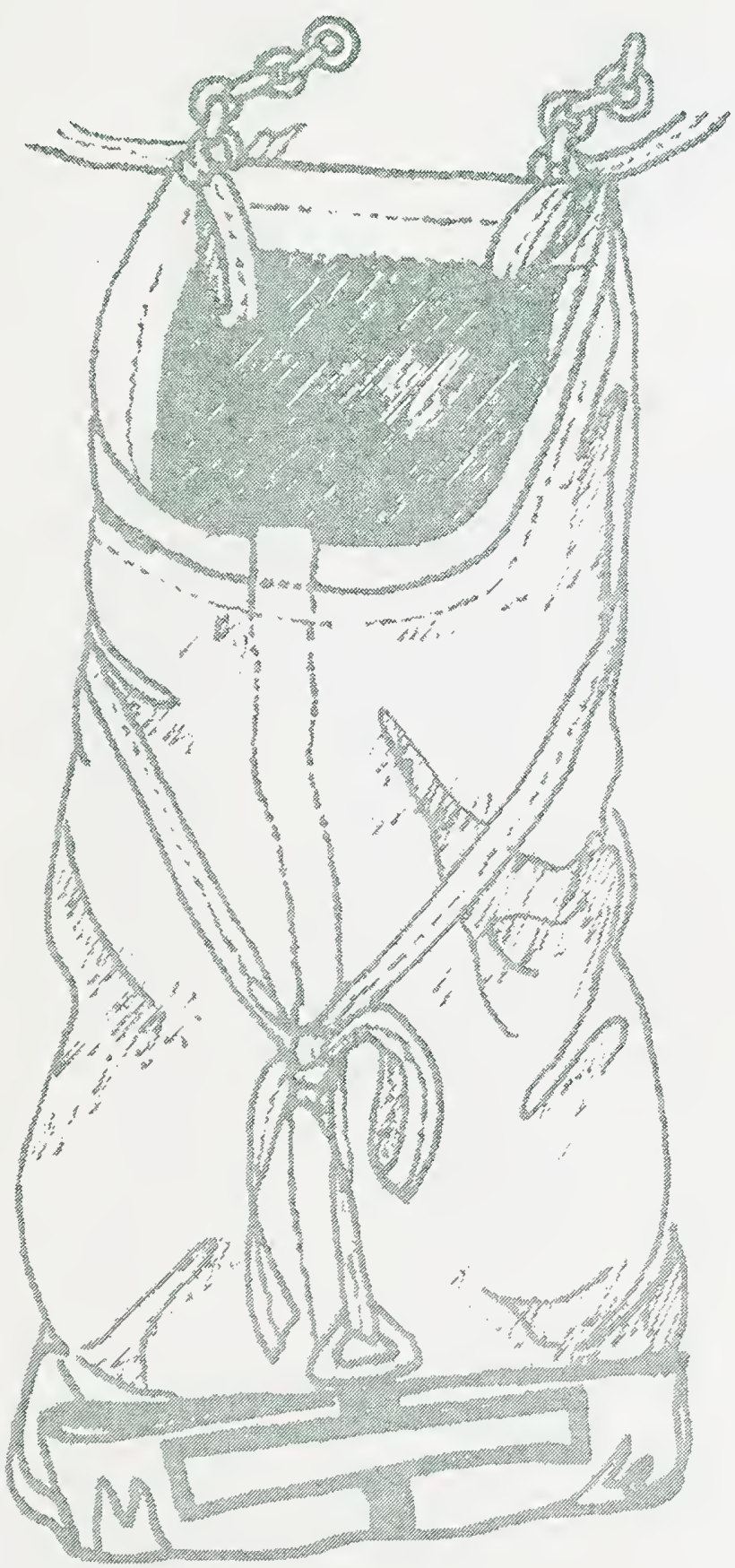


Department of

Agriculture

Tational figriculfural Thbrary 


\section{Gravel Bags for Packstock}
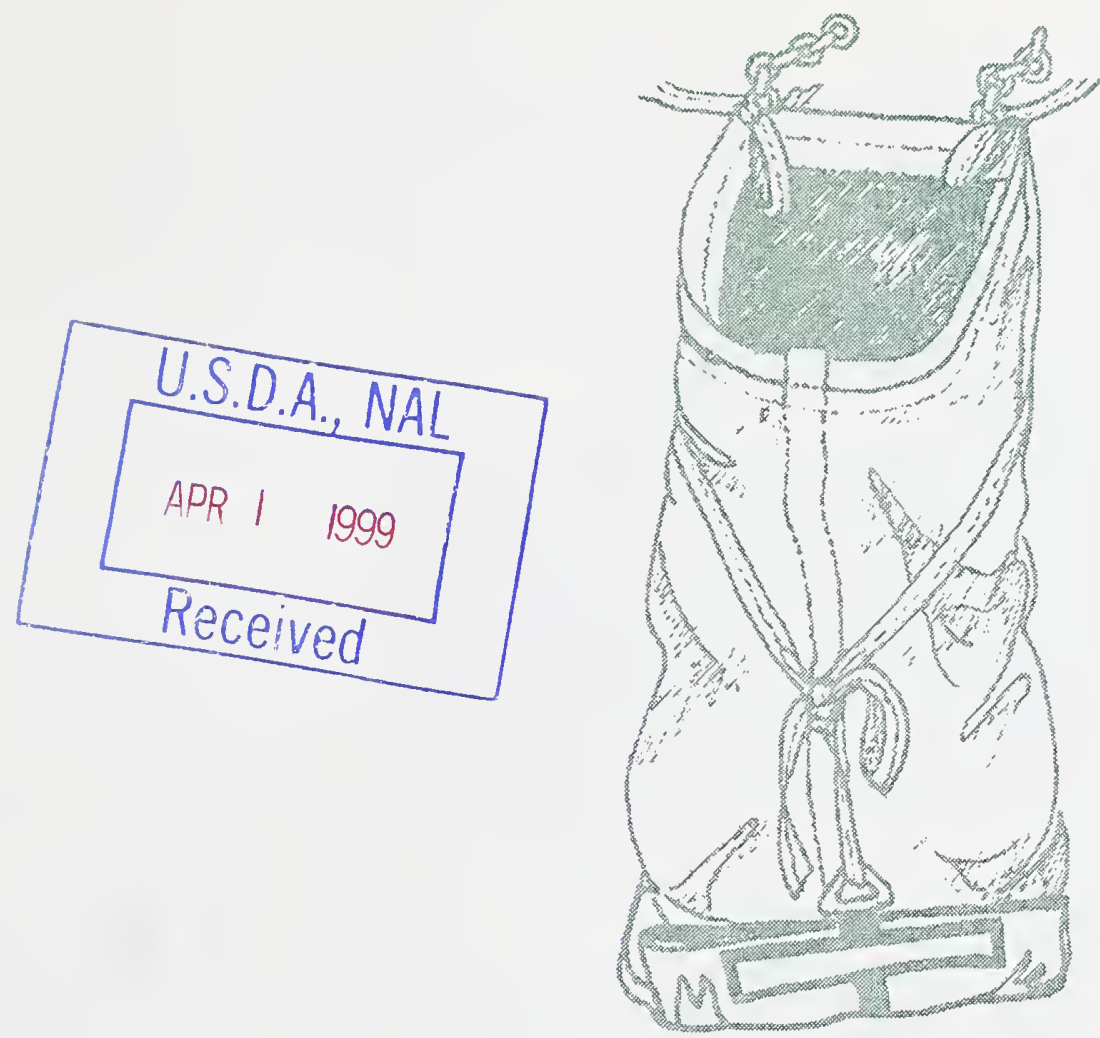

\section{Brian Vachowski \\ Project Leader}

Technology \& Development Program Missoula, Montana 59801

5E52A59

Gravel Bags for Packstock

June 1995

The contents of the publication are not to be used for advertising, publication, or promotional purposes. The Forest Service, United States Department of Agriculture has developed this information for the guidance of its employees, its contractors, and its cooperating federal and state agencies, and is not responsible for the interpretation or use of this information by anyone except its own employees. The use of trade, firm, or corporation names in this publication is for the information an convenience of the reader, and does not constitute an endorsement by the Department or any product or service to the exclusion of others that may be suitable.

The Forest Service is a diverse organization comitted to equal opportunity in employment and program delivery. USDA prohibits discrimination on the basis of race, color, national origin, sex, religion, age, disability, political affiliation and familial status. Persons believing they have been discriminated against should contact the Secretary, U.S. Department of Agriculture, Washington, D.C. 20250; or call (202) 720-7327 (voice); or (202) 720-1127 (TOD). 


\section{Contents}

Introduction

Gravel Bag Designs 2

Fruit Picking Bags 3

Testing 4

Gravel Bag Test Results 5

Recommended Design 6

Gravel Hauling Panniers 6

Sources 6

Fabrication Plans 7

\section{Acknowledgment}

\section{Techinical Assistance:}

Maggie Brinks, Missoula, Montana

Ivan Carper, Wallowa, Oregon

Mike Dolfay, Wenatchee, Washington

Brenda Holland, $\mathcal{M T D C}$

George Jackson, $\mathcal{M T D C}$

Patti Johnston, Lewis and Clark National Forest

Iim Kautz, $\mathcal{M T D C}$

Ray Mills, Lewis and Clark $\mathcal{N}$ ational Forest

Taylor Or, Gallatin National Forest

Tony Petrilli, Northern Region Smokejumper

Professional Wilderness Outfitters Association

Sara Lustgraaf, MTDC 
A fabric bag for hauling gravel or fill material with packstock is available for Forest Service use. Replacement fill material is often needed for trail work, especially for turnpike construction and tread maintenance. Using packstock to haul gravel or other fill material is practical when motorized equipment is impractical or not allowed.

The Missoula Technology and Development Center (MTDC) was asked to develop plans, and fabricate and test fabric bags that could be mounted on packsaddles. MTDC worked from a design developed in the 1970's by retired Wallowa-Whitman National Forest (R-6) employee Ivan Carper. Missoula smokejumper Tony Petrilli fabricated the bags for MTDC in 1994 and they were tested on a partnership turnpike construction project on the Rocky Mountain Ranger District of the Lewis and Clark National Forest (R-1) that same year. MTDC also tested and evaluated some bags that closely followed the original Carper design built by the Professional Wilderness Outfitters Association (PWOA), and some off-the-shelf fruit picking bags.

Included in this report are test results, recommendations, a design pattern, and some alternatives.

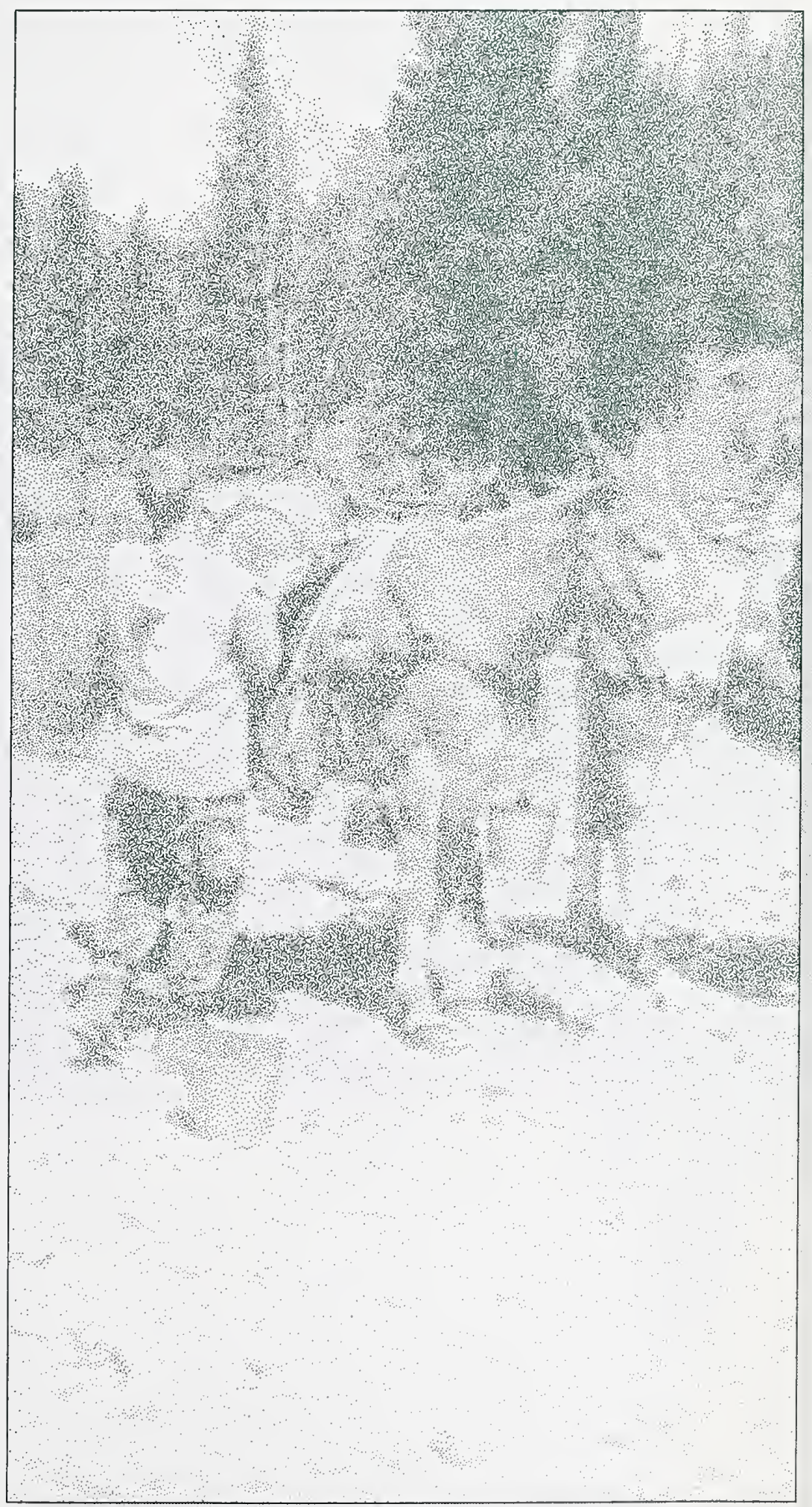




\section{Gravel Bag Designs}

Heavy canvas and liberal use of leather and rivets for reinforcement around a steel hoop make up the basic design developed by Ivan Carper. MTDC modified the design in several ways (Figure 1). Overall dimensions were kept the same as the original, but 16-ounce (455-gram) coated nylon Cordura ${ }^{\text {TM }}$ was used instead of canvas. MTDC did not use leather or rivets, but relied instead on sewn seams, which are stronger. MTDC also used tubular nylon instead of manila rope for the release cord. The bags were rigged with

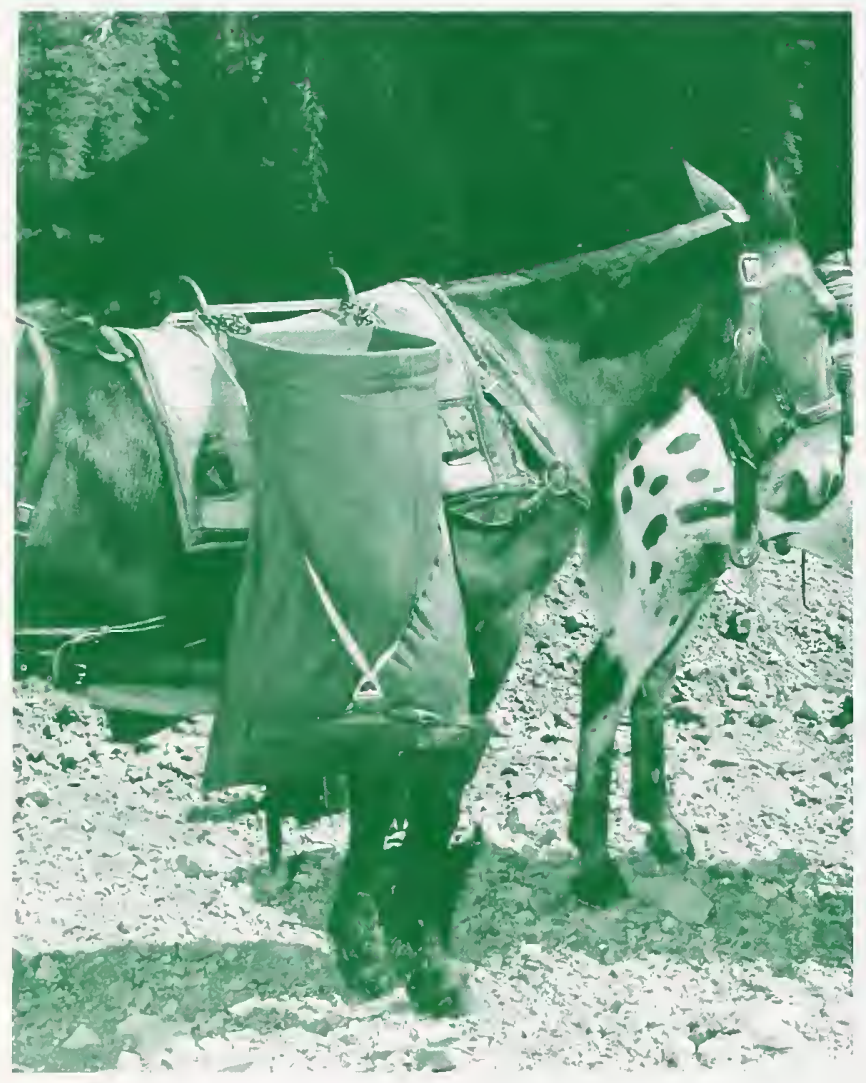

Figure 1.-Gravel bag design features sewn seams around a steel hoop. Release strap was changed slightly in final design. short chains and a snap clip to fit a decker saddle. With minor modifications, the bags could be rigged for a sawbuck packsaddle.

Partners in the testing and work project, the Professional Wilderness Outfitters Association, also fabricated some gravel bags using the basic Carper design. Theirs featured "truck tarp" fabric instead of canvas, manila release ropes, and rivets instead of sewn seams (Figure 2).

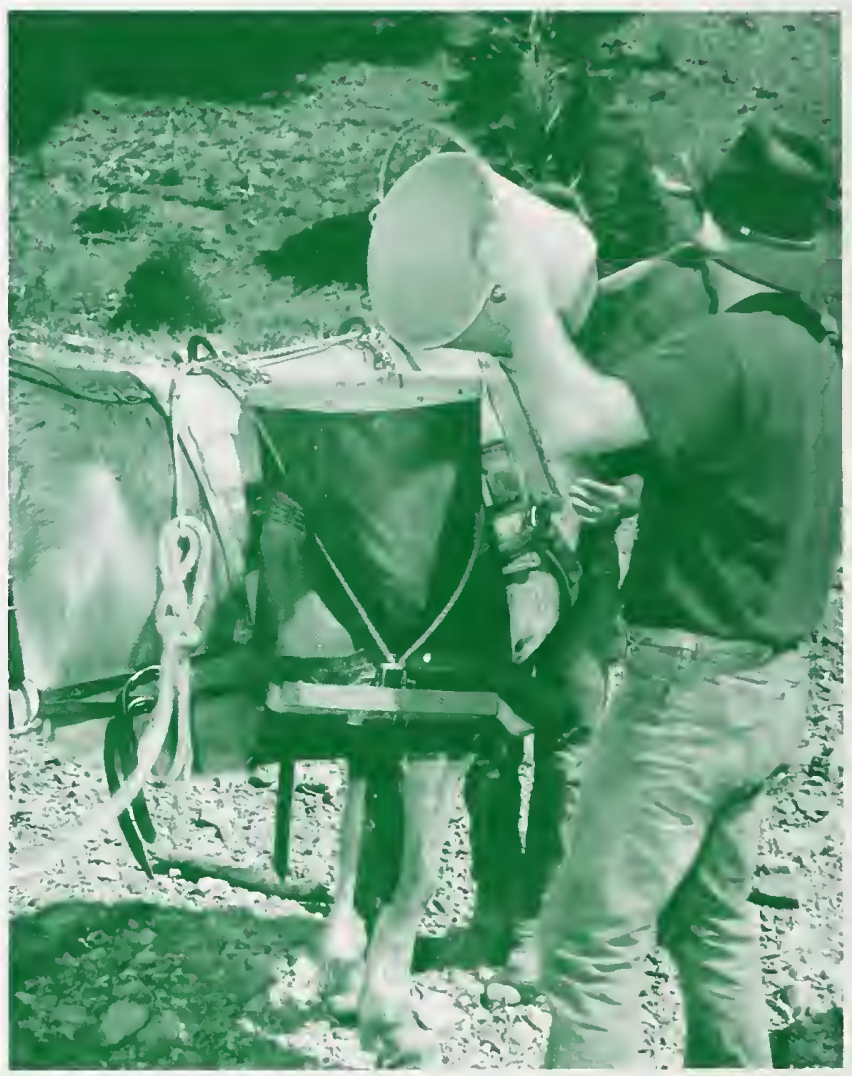

Figure 2.-This design is similar to the first, but has riveted seams and truck tarp fabric. Bags were filled one bucket at a time. Gloves should have been worn. 


\section{Fruit Picking Bags}

Based on a report from Mike Dolfay on the Wenatchee National Forest (R-6) that trail contractor Pete Harvill had been successfully using inexpensive, off-the-shelf fruit picking bags to haul gravel with his string, we included two different sets of these bags in the test. These were Wells \& Wade \#80 Super picking bag, and Citrus Bag with Rope Hook. These bags (Figure 3), while admittedly not designed to haul gravel on the side of a mule, readily fit a decker saddle with no modification. Instead of being released by jerking a knot, the load had to be released by getting close to the animal and lifting the loaded bag of gravel enough to lift the hook off the side of the bag. The hoop at the top of the bag was smaller and not as strong as the steel hoops on the other designs.

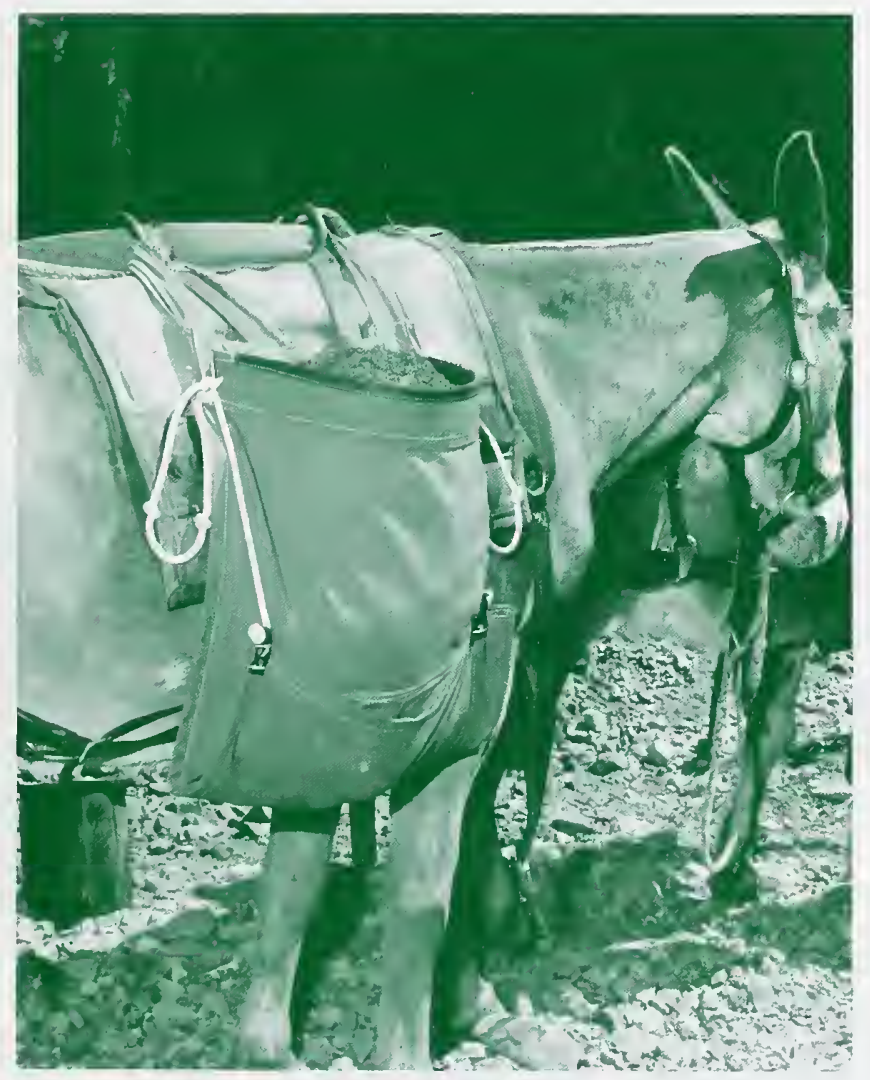

Figure 3.-Fruit picking bags require lifting the load to release the rope clips.

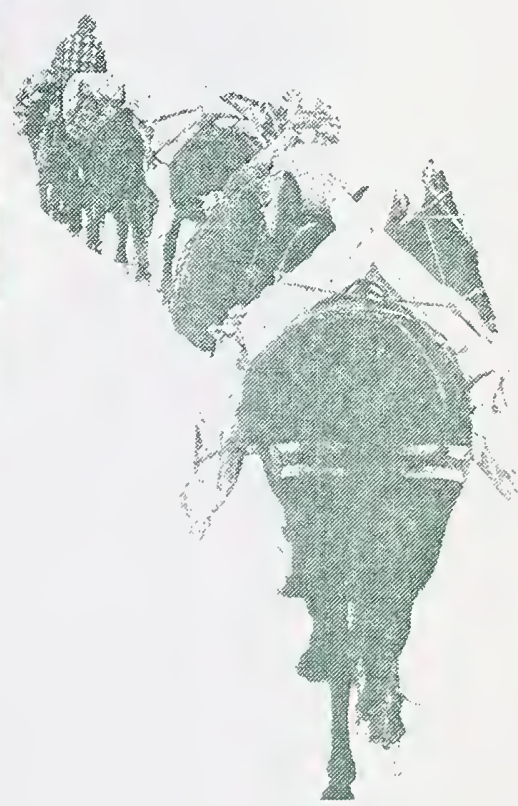


For 8 days in June, 1994, up to 24 head of mules packed gravel for a 3/4mile (1.2-kilometer) stretch of new turnpike construction on the South Fork Sun Trail No. 202. The packstock belonged to members of PWOA. They also provided workers at the gravel source to work alongside the Forest Service crew.

Each bag was tested by carrying about eight loads per day for 8 days (64 trips). The gravel was hauled from a river bottom gravel bar, up a hill approximately $1 / 2$ mile (.3 kilometer) to the turnpike construction site.

Both Carper design bags were loaded with about 160 pounds (72 kilograms) per bag, for a total load of 320 pounds (144 kilograms) per mule. The outfitters believed the mules could handle that load for short distances, but about 120 pounds (54 kilograms) per bag would be better for longer hauls. It was easy to overload the animals. In fact, the initial loads weighed 200 pounds (90 kilograms) per bag until they were better calibrated.

Because of their smaller dimensions and lighter construction, the fruit picking bags could hold only about 80 pounds (36 kilograms) of gravel per bag.

Each mule string was led through the gravel pit area, with workers on each side filling bags a bucket at a time. The bags were quiet, although the metal buckets were not. When all the mules in the string were loaded, they were led to the turnpike. Two workers were stationed there, one to hold the mule and the other to unload it one side at a time. The packstring was separated during unloading. This proved to be the most difficult procedure, since the mules varied in temperament and some were quite contentious.

Because of the difficulty of positioning some of the mules exactly where the gravel was needed, the ability to direct the flow of gravel from the bag by pulling the rope on the bottom was very useful (Figure 4). Also, by lifting up on the rope, the flow of gravel could be halted and redirected to a slightly different spot.

In all cases, the empty bags were left mounted on the packsaddles, tied and adjusted, ready for the next load.

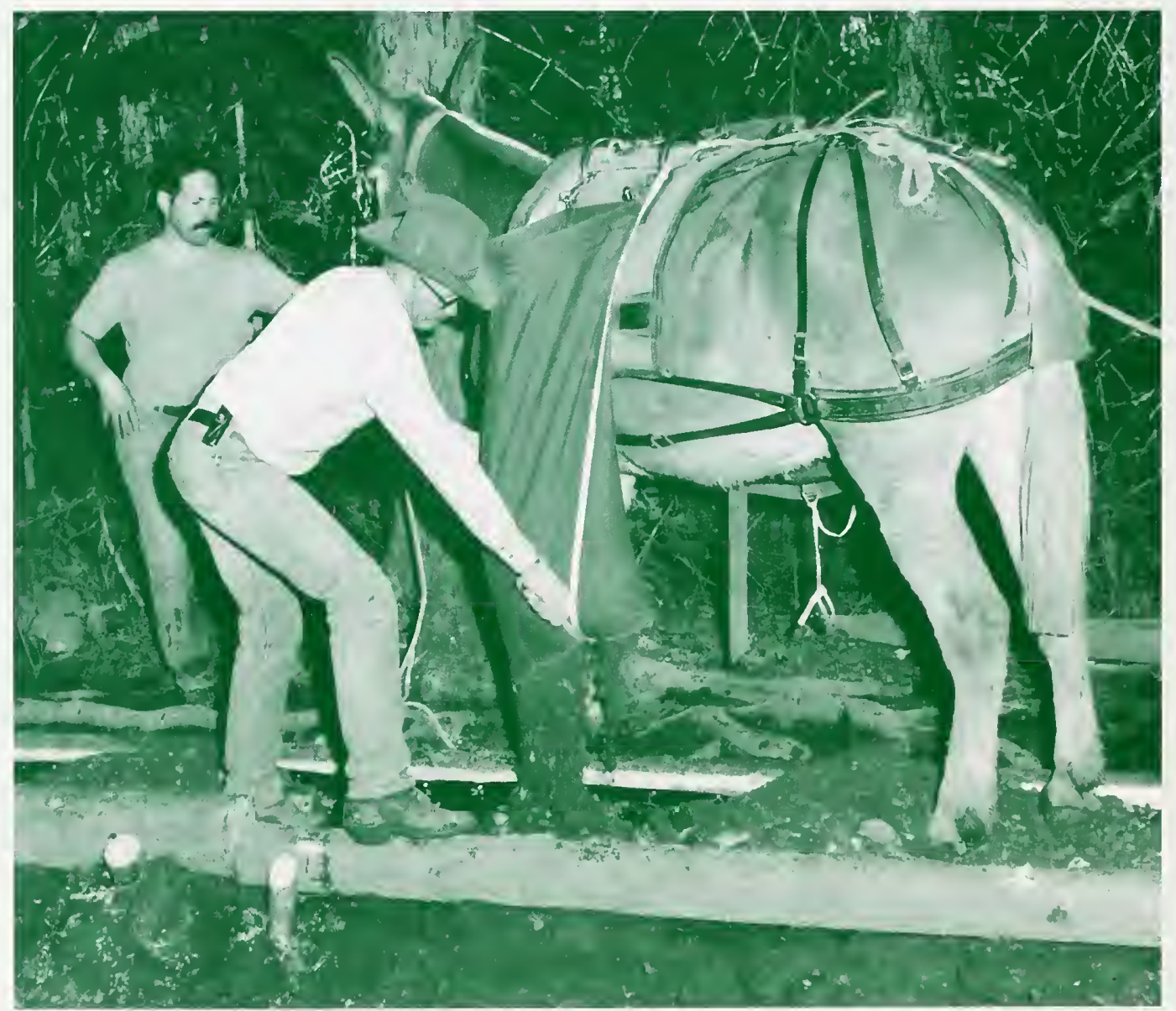

Figure 4.-Bags allow directing the flow of material under or away from the pack animal. 
Table 1 compares test results of the two versions of Ivan Carper's design and the fruit picking bags. The MTDC bag proved to be most efficient. Fruit picking bags would be adequate for lightweight jobs.

Table 1.-Packstock Gravel Bag Test Results

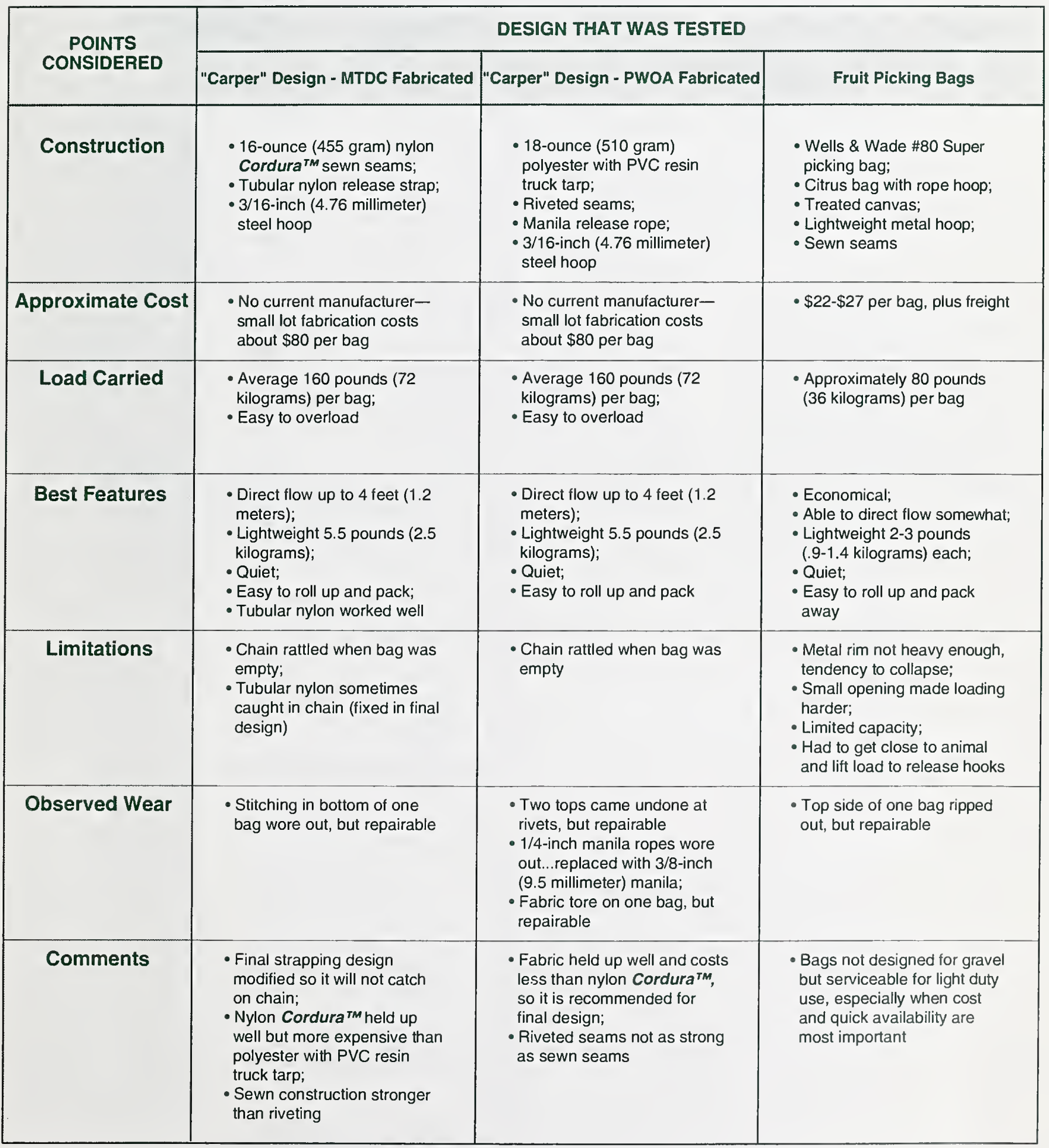


Recommended Design

Ivan Carper's design as modified by MTDC is the recommended bag. Fabrication plans are included in this report. The design is sized to the original specifications, but is modified to require sewn seams and a slightly different load release rigging. Although the bags originally fabricated by MTDC used 16-ounce (455-gram) nylon Cordura $^{\mathrm{TM}}$, the recommended plans call for 18-ounce (510-gram) polyester with PVC resin truck tarp material, a less costly yet durable fabric that held up well in the bags made by the outfitters. Cordura ${ }^{T M}$ could also be substituted if desired.

The fruit picking bags could be considered serviceable for light duty use, especially when initial cost outlay and quick availability of an off-the-shelf product are the most important considerations. The bags do not quite utilize the full load capability of pack mules, and are unlikely to stand up to sustained heavy-duty use. They may be a good alternative to hauling gravel in buckets or wheelbarrows in many instances.

\section{Gravel Hauling Panniers}

\section{Sources}

Hard-sided panniers were not evaluated in the tests. Often fitted with hinged drop doors, these have been around for many years. Often gravel would bind or break the hinges, the boxes are bulky, and most designs provided no way to direct the gravel on its way out of the box.

Improved aluminum gravel panniers, featuring a sliding, rather than a hinged door, are available from Wyoming Outdoor Industries, Inc. Similar panniers have been fabricated by other saddle shops. We did not evaluate hard-sided aluminum panniers, but based on reports from some who have used them, the panniers work well and are very sturdy. They are bulkier, noisy (should be lined with some type of fabric to cut down on noise), and are more expensive than fabric gravel bags. The aluminum panniers available from Wyoming Outdoor Industries, Inc., currently cost $\$ 395$ per set of two, not including rigging. Discounts are available when more than one set is ordered.
Fruit Picking Bags: The Wells \& Wade bags are manufactured by:

Superior Fruit Company PO Box 3444

Wenatchee, WA 98807-3444

Phone: (509) 662-5881

or (509) 662-6065

\section{Aluminum Gravel Panniers:}

Wyoming Outdoor Industries, Inc. 1231 13th St.

Cody, WY 82414

Phone: (307) 527-6449

Dave Fish Saddlery

1706 Brooks St.

Missoula, MT 59801

Phone: (406) 543-8566

For additional copies of this report or further information on bag fabricators, contact:

Brian Vachowski

USDA Forest Service, MTDC

Building 1, Fort Missoula

Missoula, MT 59801

Phone: (406) 329-3935 


\section{Fabrication Plans}

The schematic MTDC gravel bag pattern on page 9 shows the general layout. Plan dimensions could vary slightly based on fabric used. Fabricate a prototype before mass producing. The steel hoop should be fabricated first.

STEEL HOOP DETAIL

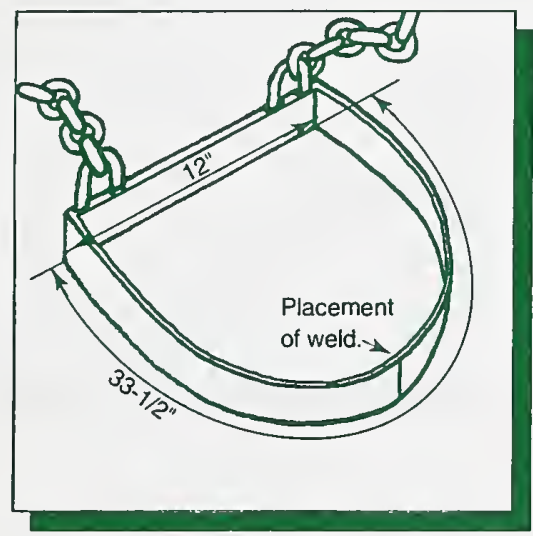

1. Steel bar is $1-1 / 4^{\prime \prime} \times 45-1 / 2 " \times 3 / 16^{\prime \prime}$.

2. From the center point of the bar, measure 6" out on each side and make $90^{\circ}$ bends on both. Now round the free ends together and weld.

3. Weld the chain links to the hoop. A carabiner or metal double snap clip can be used to connect the chains to each other. Decker saddles require 9" of chain on each side, while sawbuck saddles require 20 " per side.

\section{SEWING INSTRUCTIONS}

$\mathrm{R}=$ right side of material, and $\mathrm{W}=$ wrong side

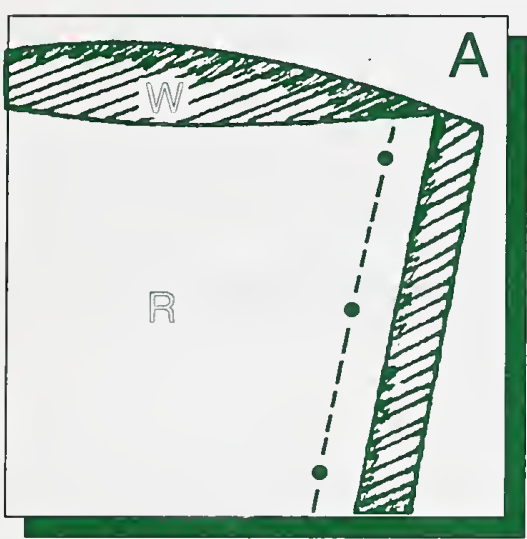

1. Fold material with wrong sides together, and match 1 " side dots with the back side 2" dots and stitch (Figure A).

2. Check to make sure the material will fit snugly around the metal hoop, then remove hoop.

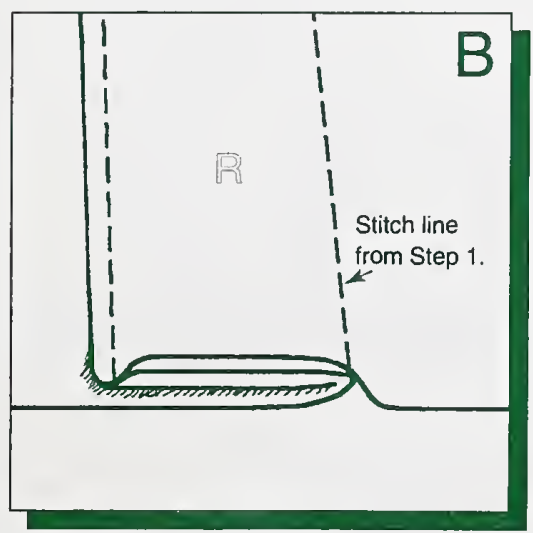

3. False Fell Seam: Fold the 2" side around the 1 " side (Figure B). Tuck by folding it again and stitching as shown. The second stitch line must be started from one end to the halfway point. Clip thread and finish stitch line from the other end. 


\section{SEWING INSTRUCTIONS, continued}

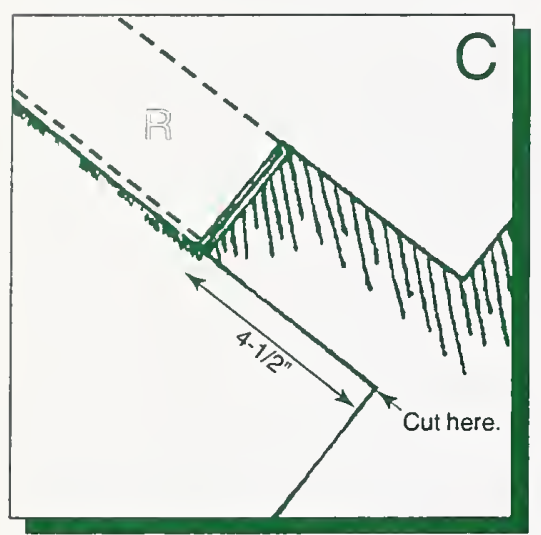

4. The hoop end will be double-folded. To reduce bulk, cut $4-1 / 2^{\prime \prime}$ of false fell seam from the hoop end (Figure $\mathrm{C}$ ).

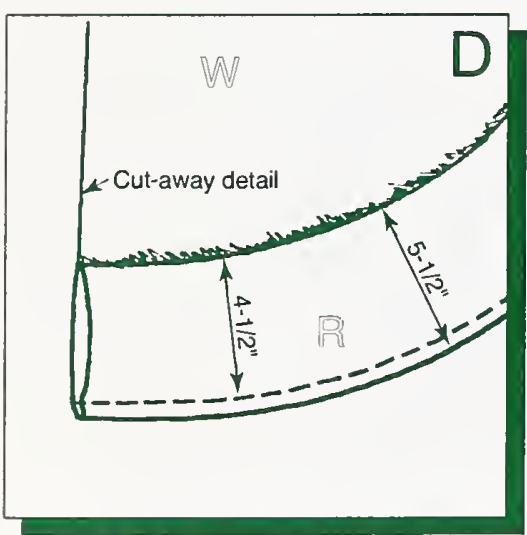

5. At the hoop end, fold at the $5 \cdot 1 / 2$ " fold line.

6. Stitch completely around on the 4-1/2" stitch line (Figure D).

7. Cut rectangular holes for hoop chain links. Use a hot-knife if material is

Cordura $^{\mathrm{TM}}$, and burn through both layers (Figure E).

8. Insert the hoop and pull the chain links up through the holes.

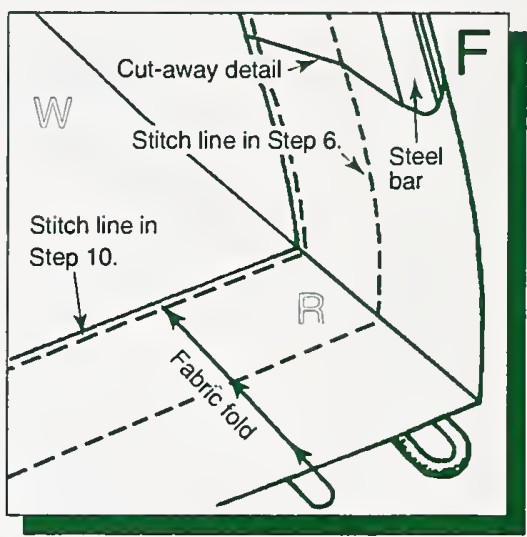

9. Fold fabric around the hoop. Hoop edge should be on the $8-1 / 2$ " fold line dots.

10. To attach the hoop inside the bag, stitch close to the fold edge on the inside of the hoop (Figure F)

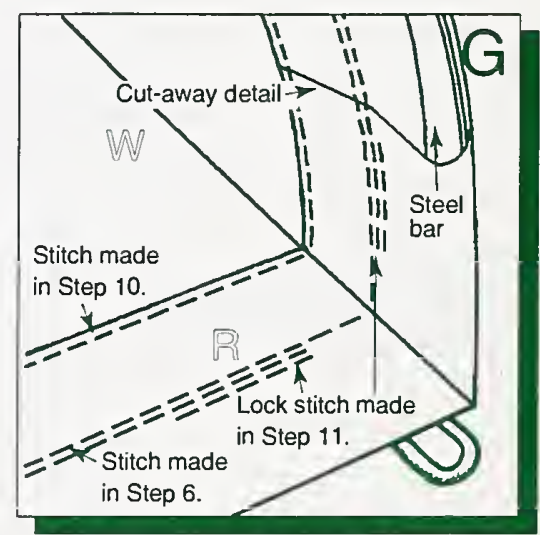

11. To secure the hoop, stitch over the stitch line created in Step 6, reinforcing it since the machine will not sew completely into the corners. Lock stitches (Figure G).

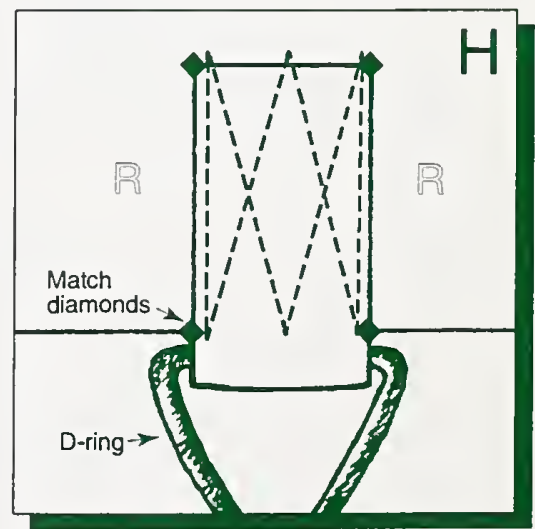

12. Bottom D-ring: Webbing 1-1/2" $x$ 10". Use 3-point, running ' $W$ ' stitch (Figure $\mathrm{H}$ ).

13. Bottom support: Material $17-1 / 2^{\prime \prime} x$ $2-1 / 2^{\prime \prime}$ with $1^{\prime \prime}$ seam tape on all four sides.

14. Attach taped piece on three sides (two long sides and one short side).

15. Insert $1^{\prime \prime} \times 16^{\prime \prime}$ steel or aluminum strip. Sew open end shut. 


\section{MGTERIGL LAYOUT}

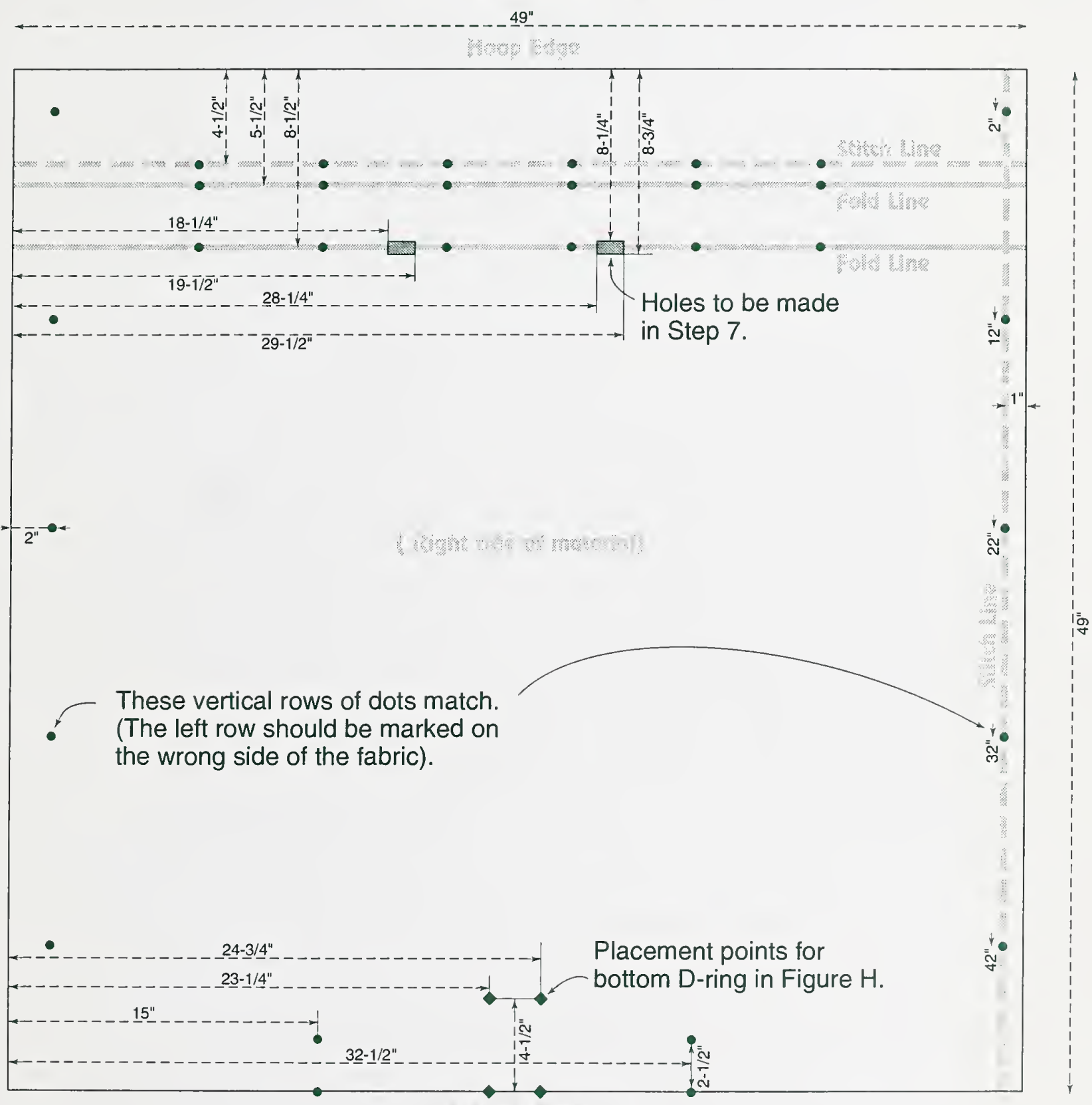

\section{MATERIALS LIST}

49" x 49", 18-ounce polyester with PVC resin, (PVC "truck tarp")* 17-1/2" x 2-1/2" 18-ounce polyester with PVC resin, (PVC "truck tarp")* $1 " \times 40$ " seam tape $1-1 / 2^{\prime \prime} \times 10^{\prime \prime}$ nylon webbing $3 / 4 "$ × 3 ' tubular nylon $3 / 4^{\prime \prime} \times 9^{\prime}$ tubular nylon
1-1/2" D-ring

$1-1 / 4^{\prime \prime} \times 16^{\prime \prime} \times 3 / 16^{\prime \prime}$ steel, or $1 / 4^{\prime \prime}$ aluminum flat stock $1-1 / 4^{\prime \prime} \times 45-1 / 2^{\prime \prime} \times 3 / 16^{\prime \prime}$ steel bar

1 medium-size carabiner or metal snap clip

2 each 9" chains for decker; or

2 each 20 " chains for sawbuck

${ }^{\star}$ Alternative material: 16 -ounce coated nylon Cordura ${ }^{\text {TM }}$ 
Notes 
NATIONAL AGRICULTURAL LIBRARY 
NATIONAL AGRICULTURAL LIBRARY

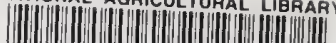

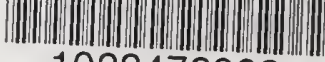

1022472803

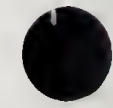

